\title{
Factors Associated with Dietary Control and Physical Activity in the Management of Metabolic Syndrome in Korean Menopausal Women
}

\author{
Guna Lee ${ }^{1}$ and Hye Young Choi ${ }^{2, *(\mathbb{D})}$ \\ 1 Department of Nursing, Cheongju University, 298 Daesung-ro, Cheongwon-gu, Cheongju 28503, Korea; \\ gunalee@cju.ac.kr \\ 2 Department of Nursing, Kangwon National University, 346, Hwangjo-gil, Dogye-eup, Samcheok-si, \\ Gangwon-do 25949, Korea \\ * Correspondence: choihy3@kangwon.ac.kr; Tel.: +82-33-540-3363
}

Received: 10 August 2020; Accepted: 13 September 2020; Published: 21 September 2020

\begin{abstract}
The increased prevalence of metabolic syndrome (MetS) among menopausal women necessitates successful management strategies such as applying dietary restrictions and engaging in physical activity to improve their health and quality of life. We investigate factors associated with dietary control and physical activity in 564 menopausal Korean women classified as having MetS who partook in the 2016 and 2017 Korean National Health and Nutrition Examination Survey (KNHANES). To determine socio-demographic characteristics, lifestyle features, and MetS-related characteristics associated with dietary control and physical activity, multiple logistic regression analysis was performed. Of the women with MetS 36.1\% applied diet control and 39.5\% engaged in physical activity. Women who applied dietary control strategies to improve their health were more likely to be in the 40-49 age group (odds ratio (OR): 3.38; 95\% confidence interval (CI): 1.25-9.18), to engage in physical activity (OR: 2.24; CI: 1.43-3.52), and to take hypertension medication (OR: 1.66; CI: 1.04-2.67) or diabetes mellitus medication (OR: 2.99; CI: 1.80-4.97). Physically active menopausal women with MetS were more likely to also engage in dieting (OR: 2.32; CI: 1.42-3.51). Accordingly, suggestions can be provided to healthcare workers in designing, not only individual approaches to lifestyle modification but also comprehensive interventions including dietary control and physical activity for menopausal MetS women. Health-care interventions like dietary control, which provide additional support to vulnerable MetS women, should target women aged 60 or above or those who do not take medicines for hypertension and diabetes mellitus.
\end{abstract}

Keywords: healthy diet; physical activity; metabolic syndrome; menopause; healthy lifestyle

\section{Introduction}

Menopause generally indicates the permanent cessation of ovulation and a decrease in estrogen and progesterone from decreased ovary activity. Estrogen deficiency occurs due from changes in body fat distribution and is associated with decreases in both vascular elasticity and endothelial cell function, as well as increases in low-density lipoprotein cholesterol [1]. Menopause is a risk factor for metabolic syndrome (MetS) as well as diabetes mellitus and cardiovascular diseases [2].

The global prevalence of MetS, which is a cluster of clinical features such as abdominal obesity, elevated triglycerides, blood pressure, plasma glucose, and reduced high-density lipoprotein (HDL) cholesterol [3], is increasing [4] and approximately $26-30 \%$ of Korean adults have MetS [5]. MetS has been associated with serious diseases, for example, diabetes, hypertension, hyperuricemia, cardiovascular diseases such as angina pectoris and myocardial infarction, stroke, and cancer, 
including breast cancer and colorectal cancer [6-8]. Various studies report that the prevalence of MetS in menopausal women is relatively higher than in premenopausal women [2,9]. Previous studies also report that MetS severity in menopausal women increases more rapidly than in pre-menopausal or peri-menopausal women [9]. This increased prevalence of MetS stimulates the necessity of MetS management in menopausal women for their health and quality of life.

Effectively managing MetS involves a combined approach of lifestyle modification and pharmacological interventions. Various studies suggest lifestyle modifications, including dietary control and physical activity for each body weight, to ensure successful MetS management [10,11]. Concentrated lifestyle modifications result in decreased weight, blood pressure, triglycerides, and fasting glucose levels and raising HDL cholesterol levels [12-14]. Dietary control and physical activity are especially important for lifestyle modifications to regulate all components of MetS [11,15].

Several studies state that MetS risk factors include age, race, dietary type, physical activities, and smoking [9-12]. However, there are insufficient data to prove the association between compliance with a healthy lifestyle and individual lifestyle characteristics or patterns [16,17]. Furthermore, factors associated with healthy lifestyle-including socio-demographic data and lifestyle features of menopausal MetS women-are nearly unknown. Therefore, in the current study, we aim to investigate factors, grouped by socio-economic status, lifestyle, and MetS status, associated with dietary control and physical activity in menopausal women with MetS, using a representative sample of Koreans.

\section{Materials and Methods}

\subsection{Study Design}

This secondary data analysis study, built on the Korean National Health and Nutrition Examination Survey (KNHANES), investigated MetS status and associated factors of dietary control and physical activities, targeting menopausal adult women with MetS.

\subsection{Subject}

This study used data from the seventh primary year (2016) and secondary year (2017) of KNHANES, conducted by the Korea Centers for Disease Control and Prevention (KCDC). The inclusion criteria for the study population were menopausal women aged 19-65 years who fall into the MetS category. The final 564 eligible people were selected by analysis from 16,277.

\subsection{Data Collection}

This study used subject-unidentifiable data in accordance with KNHANES' data provision and processing procedures. The subject sample from the seventh KNHANES were chosen from the most recently conducted Population and Housing Census Survey (2010). This study used two-stage stratified cluster sampling and systematic sampling built on the survey's boundary areas/household numbers to extract a representative sample.

This study used the following KNHANES' factors: health survey, nutrition survey, and examination. The health survey and examination were conducted at a mobile examination center, and the nutrition survey was conducted by visiting the subjects' house. The surveys were conducted using 1:1 interviews between the examiner and examinees, or by self-entry method, depending on the questionnaire's details. The examination was performed with direct measurement, observation, and sample analysis. The examination team consisted of a nurse, nutritionist, public health specialist, and people who examined performance ability through level education, and on-site quality supervision.

To perform the secondary data analysis, institutional review board exemption approval was obtained from the affiliated university (Approved No. KWNUIRB-2020-01-010). 


\subsection{Variables}

\subsubsection{Socio-Demographic Characteristics}

Subjects' age, education and income level, and co-residence were investigated. The researchers classified subjects' age (40s, 50s, 60s), education level (under elementary-school graduate, middle-school graduate, high-school graduate, or above-college graduate), income level (household income quartile: low, mid-low, mid-high, or high), and co-residence (cohabitation or non-cohabitation).

\subsubsection{Lifestyle Features}

The researchers investigated subjects' current smoking, drinking, physical activity, and dietary controls. Answers to the question as to whether the subject currently smokes were classified into "Yes (smoking)" or "No (not smoking)." Answers to the question regarding how frequently the subject drank during the last year were classified into "Yes (drinking)" and "No (not drinking)." Answers to the subject's physical activity (if they practiced over $2 \mathrm{~h} 30 \mathrm{~min}$ per week of mid-intensity physical activity or over $1 \mathrm{~h} 15 \mathrm{~min}$ per week of high-intensity physical activity or mid-mixed-high-intensity physical activity ( 1 min of high-intensity physical activity equals 2 min of mid-intensity physical activity)) were classified into "Yes (practiced)" and "No (not practiced)" as the seventh KNHANES" guideline by the Korea Centers for Disease Control and Prevention (KCDC) [18]. Regarding dietary control status, answers to the question of whether the subject is currently under dietary control due to special circumstances were classified as "Yes" and "No." For those who answered "Yes," the reasons were investigated and reclassified as "Disease," "Weight control," or "Others."

\subsubsection{MetS}

In this study, those who showed more than three symptoms including abdominal obesity, high blood pressure, hypertriglyceridemia, low HDL cholesterol, and hyperglycemia, were defined as MetS. In addition, these MetS subjects were classified into " 3, " " 4 ," and " 5 ." Guidelines from the 2005 Adult Treatment Panel III (ATP III) [19], conducted by the American Heart Association (AHA)/The National Heart, Lung, and Blood Institute (NHLBI), were the standard used for MetS diagnosis. In addition, to apply to the Korean situation, the 2014 standard of the Korean Society for Study of Obesity was used for abdominal obesity [20]. Specific standards of MetS diagnosis in this study are as follows:

- Waist circumference: values of $\geq 85 \mathrm{~cm}$ for women

- Blood pressure: systolic pressure $\geq 130 \mathrm{mmHg}$ or diastolic pressure $\geq 85 \mathrm{mmHg}$ (or those taking hypertension-related medicines).

- Triglyceride: values of $\geq 150 \mathrm{mg} / \mathrm{dL}$ (or those taking dyslipidemia-related medicines).

- HDL cholesterol: values of $\leq 50 \mathrm{mg} / \mathrm{dL}$ for women (or those taking dyslipidemia-related medicines).

- Fasting blood sugar: values of $\geq 100 \mathrm{mg} / \mathrm{dL}$ (or those taking diabetes-related medicines).

Medicine usage for hypertension, dyslipidemia, or diabetes was investigated regarding current drug treatment status. Furthermore, the subjects' status was categorized as "Yes (currently taking)," "No, with diagnosis" or "No, without diagnosis."

\subsection{Data Analysis}

The data were analyzed using SPSS version 24.0 (IBM Corp., Armonk, NY, USA). Differences were considered statistically significant at $p<0.05$. Socio-economic status, lifestyle, and MetS status were reported as the average/standard error, frequency, and percentage applying weight. Furthermore, differences in dietary control and physical activity were compared by socio-economic status, lifestyle, and MetS variables, which comprise the number of MetS and each component of MetS, using chi-square test and t-test in complex sample analysis. Lastly, multiple logistic regression in complex sample 
analysis was performed to identify influencing factors which are grouped by socio-economic status, lifestyle, and MetS status represented by the variable of the number of MetS on dietary control and undertaking physical activity.

\section{Results}

\subsection{Socio-Demographic Characteristics, Lifestyle Features, and MetS-Related Characteristics of Study Participants}

Regarding the subjects' general characteristics, the average age was 57.0 years; those in their $50 \mathrm{~s}$ were most common (50.6\%), those in their $60 \mathrm{~s}$ totaled $34.9 \%$; and those in their $40 \mathrm{~s}$ totaled $9.1 \%$. The highest-ranking education level was high school graduate ( $34.1 \%$ of subjects), then elementary school graduate $(29.9 \%)$, middle school graduate $(21.5 \%)$, and college graduate $(14.5 \%)$. Income levels were similar among the subjects. Mid-high-income levels totaled $28 \%$ of subjects, mid-low-income levels totaled $27.6 \%$, and high-income levels totaled $25.7 \%$. The low-income level group was the smallest group, with $18.7 \%$ of subjects. Lastly, those with co-habiting members totaled $91.3 \%$ and those with none totaled $8.7 \%$.

The lifestyle survey results showed that $60.3 \%$ of subjects were current drinkers, $4.1 \%$ current smokers, $39.5 \%$ physical activity performers, and $36.1 \%$ on dietary control. The reason for each subjects' dietary controls showed similar dispersion: $50.1 \%$ due to weight control, $46.7 \%$ due to illness, and $3.2 \%$ for other reasons.

Regarding MetS-related characteristics, the average accompanying number of MetS-diagnosed components was 3.6. Those with three components totaled 50.6\%, the largest group; those with four components totaled 35.0\%; and those with five components totaled 14.3\%. Among MetS-diagnosed components, subjects' average waist measurement was $86.0 \mathrm{~cm}$, and $54.9 \%$ of those subjects had abdominal obesity. The average systolic pressure was $125.9 \mathrm{mmHg}$, the average diastolic pressure was $79.3 \mathrm{mmHg}$, and $69.0 \%$ of subjects had high blood pressure. The average triglyceride was $185.6 \mathrm{mg} / \mathrm{dL}$, and $83.0 \%$ of subjects had high triglyceride. The average HDL cholesterol was $47.6 \mathrm{mg} / \mathrm{dL}$, and $87.6 \%$ of subjects had high HDL cholesterol. Lastly, the average blood sugar level was $113.7 \mathrm{mg} / \mathrm{dl}$, and $69.1 \%$ of subjects had high blood sugar.

As for drug-treatment-related characteristics, specifically regarding hypertension treatment, $56.0 \%$ of subjects were not taking medicines because they had not been not diagnosed by a doctor; among those having undergone a doctor's diagnosis, $42.2 \%$ were taking medicines, and $1.8 \%$ of subjects were not taking medicines. Regarding medicinal dyslipidemia treatment, $47.6 \%$ of subjects were not taking medicines because they had not been diagnosed by a doctor; after a doctor's diagnosis, $47.6 \%$ were taking medicines, and $10.5 \%$ were not taking medicines. In the case of diabetes mellitus treatment, $78.0 \%$ of subjects were not taking medicines because they had not been diagnosed by a doctor; after a doctor's diagnosis, $21.8 \%$ were currently taking medicine, and $0.1 \%$ were not taking medicines (Table 1).

\subsection{Differences in Dietary Control Status According to Sociodemographic, Lifestyle and MetS-Related Characteristics}

Dietary control status analysis according to sociodemographic characteristics was significantly different in age $\left(\chi^{2}=346.59, p<0.001\right)$, education level $\left(\chi^{2}=206.02, p<0.001\right)$, income level $\left(\chi^{2}=20.95\right.$, $p=0.021)$, and co-residence $\left(\chi^{2}=17.87, p=0.001\right)$. The group on dietary control showed an average age of 56.2, significantly lower than the group who are not on dietary control, which was 57.4 years $(t=4.53, p=0.034)$. According to education level, higher percentages of those on dietary control were elementary school graduates $(33.0 \%, 28.3 \%)$ and college graduates $(17.4 \%, 12.6 \%)$ than those who are not, relatively less so in middle school graduates. As for subjects' income level, the dietary control group showed higher percentages of people in the "high-income" group (31.5\%, $22.1 \%)$ and lower percentages in the "low," "mid-low," and "mid-high-income" groups. The dietary control group 
showed a higher percentage of people in the non-cohabitation group regarding the co-residence status $(9.5 \%, 3.3 \%)$.

Table 1. Differences in Dietary Control by Sociodemographic, Lifestyle and metabolic syndrome (MetS) Characteristics.

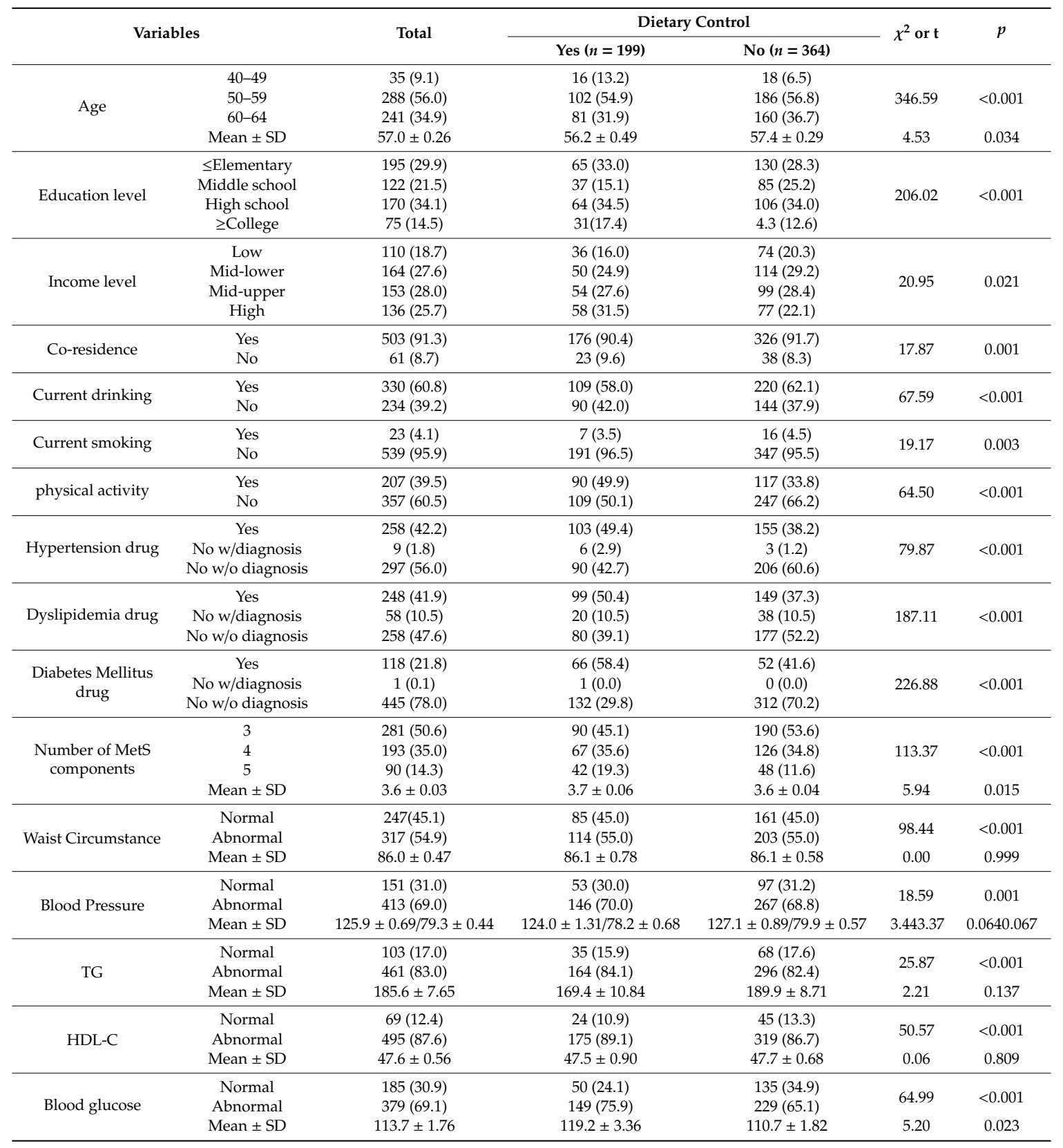

Mean \pm SD: Mean \pm standard daviation; TG: Triglyceride; HDL-C: HDL cholesterol.

Dietary control status according to healthy lifestyle was significantly different in the current drinking $\left(\chi^{2}=67.59, p<0.001\right)$, current smoking $\left(\chi^{2}=19.17, p=0.003\right)$ and physical activity groups $\left(\chi^{2}=64.50, p<0.001\right)$. There were more current drinkers in the non-dietary control group $(62.1 \%)$ than in the dietary control group (53.0\%) and current smokers showed the same type of result $(4.5 \%, 3.5 \%)$. In contrast, there were more physical activity performers in the dietary control group (49.9\%) than in the non-dietary control group (33.8\%).

Dietary control status according to MetS characteristics was significantly different in the hypertension drug treatment $\left(\chi^{2}=79.87, p<0.001\right)$, dyslipidemia drug treatment $\left(\chi^{2}=187.11\right.$, $p<0.001)$, diabetes drug treatment $\left(\chi^{2}=226.88, p<0.001\right)$ and accompanying number of MetS 
components groups $\left(\chi^{2}=113.37, p<0.001\right)$. In addition, dietary control status according to all MetS diagnosis components was significantly different in the abdominal obesity $\left(\chi^{2}=98.44, p<0.001\right)$, high blood pressure $\left(\chi^{2}=18.59, p=0.001\right)$, high triglyceride $\left(\chi^{2}=25.87, p<0.001\right)$, low HDL cholesterol $\left(\chi^{2}=50.57, p<0.001\right)$ and high blood sugar groups $\left(\chi^{2}=64.99, p<0.001\right)$. There was more hypertension drug-taking in the dietary control group $(49.4 \%, 38.2 \%)$, and the dyslipidemia $(50.4 \%, 37.3 \%)$ and diabetes mellitus drug groups $(58.4 \%, 41.6 \%)$ showed the same type of result. As for accompanying number of MetS components, the dietary control group showed an average number of 3.7 subjects and the non-dietary control group showed an average number of 3.6 subjects $(t=5.94, p=0.015)$. The group with three MetS components had fewer subjects in the dietary control group (45.1\%) than the non-dietary control group (53.6\%). Abdominal obesity was shown in $55.0 \%$ of subjects in the dietary control and non-dietary control groups. The high blood pressure $(70.0 \%, 68.8 \%)$, high triglyceride $(84.1 \%, 82.4 \%)$, low HDL cholesterol $(89.1 \%, 86.7 \%)$, and high blood sugar groups $(75.9 \%, 65.1 \%)$ all showed higher percentages of subjects in the dietary control group than the non-dietary control group. A difference also occurred in the average blood sugar level group $(t=5.20, p=0.023)$. The dietary control group showed higher blood sugar levels $(119.2 \mathrm{mg} / \mathrm{dL})$ than the non-dietary control group $(110.7 \mathrm{mg} / \mathrm{dL})$ (Table 1$)$.

\subsection{Differences in Physical Activity Status According to Sociodemographic, Lifestyle and MetS-Related Characteristics}

Physical activity status according to sociodemographic characteristics was significantly different in the age $\left(\chi^{2}=466.94, p<0.001\right)$, education level $\left(\chi^{2}=133.73, p<0.001\right)$ and income level groups $\left(x^{2}=137.56, p<0.001\right)$. In the physical activity performing group, the percentage of those in their 40s $(9.7 \%)$ and $50 \mathrm{~s}(56.5 \%)$ was higher than those in their $40 \mathrm{~s}(8.8 \%)$ and $50 \mathrm{~s}(55.6 \%)$ in the non-performing group. As for education level, there were more subjects in the physical activity performing group $(40.7 \%)$ with high school grades than in the non-performing group $(29.8 \%)$. In contrast, the performing group showed lower numbers of subjects for elementary school graduates, middle school graduates, and college graduates than the non-performing group. Regarding income level, the physical activity group showed fewer subject in the "low-income" group $(14.3 \%, 21.6 \%)$, and showed higher subject numbers in the "mid-low," "mid-high," and "high-income" groups.

Physical activity status according to lifestyle significantly differed in the current drinking group $\left(\chi^{2}=48.53, p<0.001\right)$, dietary control status $\left(\chi^{2}=64.50, p<0.001\right)$ and reason for dietary control $\left(\chi^{2}=35.57, p<0.001\right)$. Current drinkers had lower numbers in the non-physical activity performing group $(59.4 \%)$ than in the performing group $(62.8 \%)$. The percentage of those on dietary control was higher in the physical activity performing group (45.5\%) than in the non-performing group $(30.0 \%)$. Regarding the reason for dietary control, the physical activity group $(50.6 \%)$ showed higher subject numbers for "weight control" purposes than the non-performing group (49.5\%).

Lastly, physical activity status according to MetS characteristics significantly differed in hypertension drug treatment $\left(\chi^{2}=143.36, p<0.001\right)$, dyslipidemia drug treatment $\left(\chi^{2}=34.29\right.$, $p<0.001)$, diabetes mellitus drug treatment $\left(\chi^{2}=53.96, p<0.001\right)$ and accompanying number of MetS components groups $\left(\chi^{2}=131.20, p<0.001\right)$. In addition, physical activity status according to all MetS components also significantly differed in abdominal obesity $\left(\chi^{2}=32.59, p<0.001\right)$, high blood pressure $\left(\chi^{2}=77.10, p=0.001\right)$, high triglyceride $\left(\chi^{2}=31.75, p<0.001\right)$, low HDL cholesterol $\left(\chi^{2}=65.91\right.$, $p<0.001)$ and high blood sugar groups $\left(\chi^{2}=83.97, p<0.001\right)$. There were fewer subjects under high blood pressure drug treatments resulting from a doctor's diagnosis in the physical activity performing group $(37.6 \%, 45.1 \%)$. Those under dyslipidemia $(41.7 \%, 42.1 \%)$ and diabetes drug treatments $(20.3 \%$, $21.3 \%$ ) showed similar results. As for an accompanying number of MetS components, the group, which had three MetS components had higher numbers in the physical activity group $(54.0 \%)$ than in the non-performing group (48.5\%). In contrast, abdominal obesity had fewer subject numbers in the physical activity performing group (48.6\%) than in the non-performing group (59.0\%). Furthermore, average waist measurement showed lower numbers in the physical activity performing group $(84.7 \mathrm{~cm})$ 
than in the non-performing group $(86.9 \mathrm{~cm})(\mathrm{t}=8.00, p=0.005)$. High blood pressure $(68.0 \%, 69.7 \%)$ and high triglyceride groups $(81.5 \%, 84.0 \%)$ also showed similar results. However, low HDL cholesterol $(88.9 \%, 86.8 \%)$ and high blood sugar groups $(71.3 \%, 67.6 \%)$ showed higher subject numbers in the physical activity performing group than in the non-performing group (Table 2).

Table 2. Differences in Physical Activity by Sociodemographic, Lifestyle and MetS Characteristics.

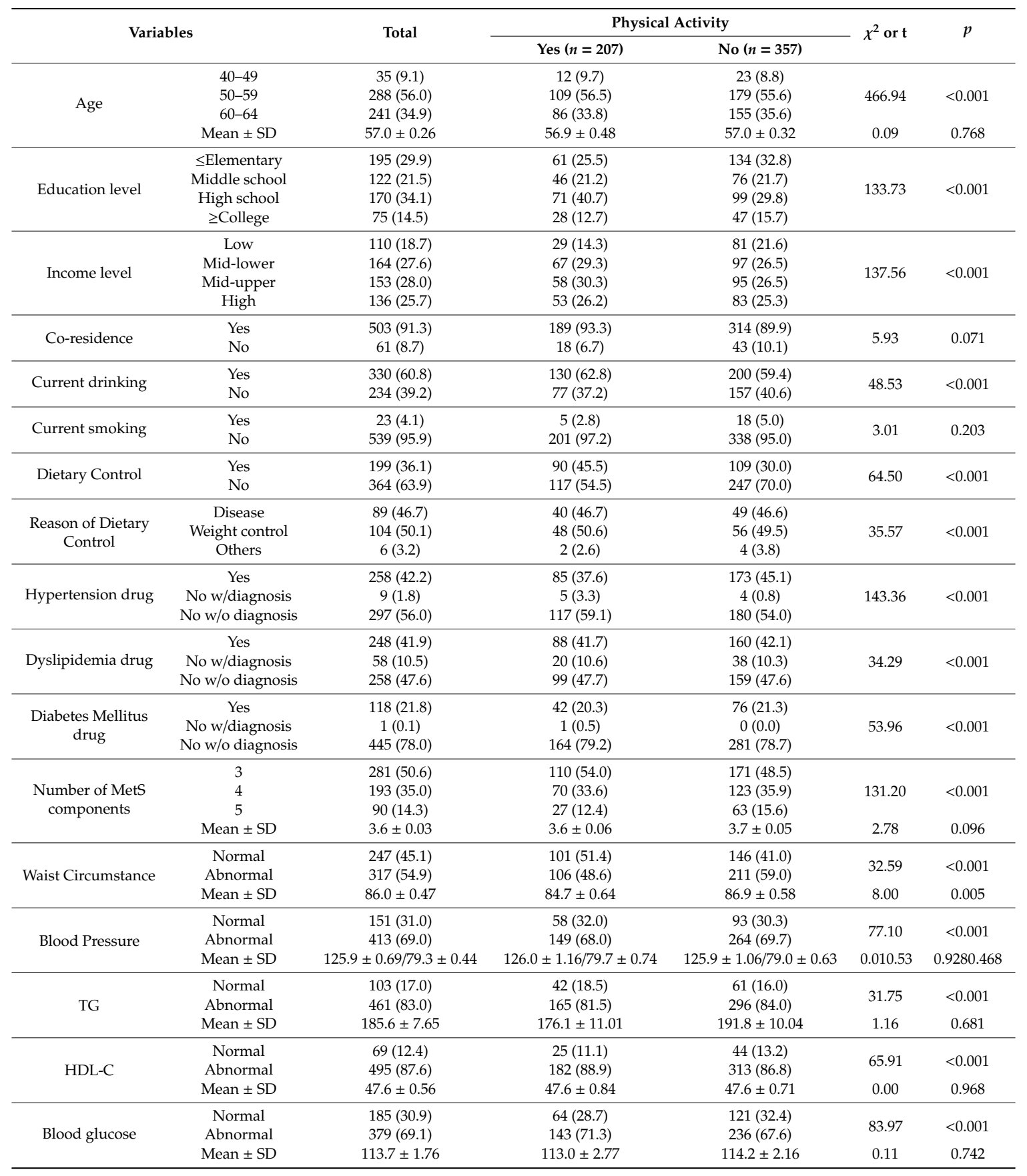

\subsection{Associated Factors of Dietary Control}

Table 3 presents the odds ratios (OR) for dietary control according to sociodemographic and lifestyle factors, and MetS characteristics (Table 3). The results show that age, physical activity status, hypertension drug treatment status, and diabetes drug treatment status are the most significant lifestyle modification factors for MetS. Subjects in their 40s were on dietary control 3.380 times more than those in their $60 \mathrm{~s}(\mathrm{OR}=3.380, \mathrm{CI}=1.185-6.815)$. The physical activity performing group was on dietary 
control 2.238 times more than the non-performing group $(\mathrm{OR}=2.238, \mathrm{CI}=1.425-3.516)$. The group taking drugs after a doctor's diagnosis of hypertension were on dietary control 1.662 times more than the group not taking drugs due to never having been diagnosed with hypertension $(\mathrm{OR}=1.662$, $\mathrm{CI}=1.035-2.670)$. The group under drug treatment for a diabetes mellitus diagnosis was on dietary control 2.992 times more than the group not on diabetes drug treatments due to never having been diagnosed with diabetes mellitus $(\mathrm{OR}=2.992, \mathrm{CI}=1.801-4.971)$.

Table 3. Associated Factors of Dietary Control and Physical Activity.

\begin{tabular}{|c|c|c|c|c|c|c|c|}
\hline \multicolumn{2}{|c|}{ Variables } & \multicolumn{3}{|c|}{ Dietary Control } & \multicolumn{3}{|c|}{ Physical Activity } \\
\hline & & OR & $95 \%$ CI & $p$ & OR & $95 \% \mathrm{CI}$ & $p$ \\
\hline \multirow{3}{*}{ Age } & $40-49$ & 3.380 & $1.245-9.178$ & 0.017 & 0.662 & $0.279-1.571$ & 0.348 \\
\hline & $50-59$ & 1.229 & $0.769-1.966$ & 0.388 & 0.871 & $0.560-1.354$ & 0.540 \\
\hline & $60-64$ & 1.000 & & & 1.000 & & \\
\hline \multirow{4}{*}{ Education level } & $\leq$ Elementary & 1.302 & $0.626-2.709$ & 0.479 & 0.964 & $0.454-2.049$ & 0.924 \\
\hline & Middle school & 0.517 & $0.256-1.042$ & 0.065 & 1.328 & $0.622-2.835$ & 0.463 \\
\hline & High school & 0.741 & $0.379-1.447$ & 0.379 & 1.882 & $0.914-3.875$ & 0.086 \\
\hline & $\geq$ College & 1.000 & & & 1.000 & & \\
\hline \multirow{4}{*}{ Income level } & Low & 0.513 & $0.258-1.023$ & 0.058 & 0.799 & $0.388-1.647$ & 0.543 \\
\hline & Mid-lower & 0.529 & $0.278-1.008$ & 0.053 & 1.318 & $0.733-2.371$ & 0.355 \\
\hline & Mid-upper & 0.627 & $0.339-1.159$ & 0.136 & 1.067 & $0.612-1.859$ & 0.820 \\
\hline & High & 1.000 & & & 1.000 & & \\
\hline \multirow{2}{*}{ Co-residence } & No & 1.521 & $0.812-2.848$ & 0.190 & 0.696 & $0.326-1.489$ & 0.350 \\
\hline & Yes & 1.000 & & & 1.000 & & \\
\hline \multirow{2}{*}{ Current drinking } & Yes & 0.645 & $0.415-1.004$ & 0.052 & 1.236 & $0.798-1.913$ & 0.342 \\
\hline & No & 1.000 & & & 1.000 & & \\
\hline \multirow{2}{*}{ Current smoking } & Yes & 0.769 & $0.244-2.426$ & 0.654 & 0619 & $0.194-1.977$ & 0.418 \\
\hline & No & 1.000 & & & 1.000 & & \\
\hline \multirow{2}{*}{ physical activity } & Yes & 2.238 & $1.425-3.516$ & $<0.001$ & - & - & - \\
\hline & No & 1.000 & & & - & - & - \\
\hline \multirow{2}{*}{ Dietary control } & Yes & - & - & - & 2.232 & $1.418-3.514$ & 0.001 \\
\hline & No & - & - & - & 1.000 & & \\
\hline \multirow{3}{*}{ Hypertension drug } & Yes & 1.662 & $1.035-2.670$ & 0.036 & 0.699 & $0.442-1.107$ & 0.127 \\
\hline & No w/diagnosis & 3.401 & $0.655-17.666$ & 0.145 & 2.955 & $0.611-14.033$ & 0.178 \\
\hline & No w/o diagnosis & 1.000 & & & 1.000 & & \\
\hline \multirow{3}{*}{ Dyslipidemia drug } & Yes & 1.504 & $0.932-2.427$ & 0.094 & 0.916 & $0.585-1.433$ & 0.700 \\
\hline & No w/diagnosis & 1.433 & $0.687-2.987$ & 0.337 & 0.935 & $0.477-1.830$ & 0.844 \\
\hline & No w/o diagnosis & 1.000 & & & 1.000 & & \\
\hline \multirow{3}{*}{ Diabetes Mellitus drug } & Yes & 2.992 & $1.801-4.971$ & $<0.001$ & 1.150 & $0.676-1.956$ & 0.065 \\
\hline & No w/diagnosis * & & & & & & \\
\hline & No w/o diagnosis & 1.000 & & & 1.000 & & 1.000 \\
\hline \multirow{3}{*}{$\begin{array}{l}\text { Number of MetS } \\
\text { components }\end{array}$} & 3 & 0.749 & $0.384-1.459$ & 0.395 & 1.399 & $0.694-2.820$ & 0.348 \\
\hline & 4 & 0.632 & $0.322-1.238$ & 0.181 & 1.199 & $0.607-2.369$ & 0.601 \\
\hline & 5 & 1.000 & & & 1.000 & & \\
\hline
\end{tabular}

* This group was excluded from the multiple logistic regression analysis because the subject number of this group was '1' only.

\subsection{Associated Factors of Physical Activity}

Table 3 also presents the ORs for physical activity according to sociodemographic and lifestyle factors, and MetS characteristics. The results show that dietary control status is also one of the most significant lifestyle modification factors. The dietary control group performed physical activity 2.234 times more than the non-dietary-control group $(\mathrm{OR}=2.232, \mathrm{CI}=1.418-3.514)$.

\section{Discussion}

In this current study, we examined compliance with healthy lifestyles of menopausal MetS women in Korea and analyzed associated factors of dietary control and physical activity depending on socio-economic status, lifestyle, and MetS status. There were three major findings.

First, menopausal MetS women in Korea who maintain a healthy lifestyle totaled around $35 \%$ of the subjects under study. Most participants did not smoke (95.9\%), and less than half of participants 
adhered to engaging in physical activity (39.5\%), no drinking (39.2\%), and dietary control $(36.1 \%)$. Compared with our subjects who did not smoke, MetS prevalence in these menopausal women might relate to menopausal pathology as estrogen deficiency [1,2] rather than smoking [21-23]. In this study, rates of engaging in physical activity (39.5\%) were lower compared to previous cross-sectional studies of menopausal women by Kara et al. (47\%) [24] and Mansikkamäk et al. (50.7\%) [25]. In the present study, compared with $36.1 \%$ of subjects with dietary control compliance, Cho et al. reported that more than half of study participants (52.3\%) keep healthy dietary patterns in menopausal women through dietary patterns based on dietary-intake records [26]. This discrepancy might relate to the analyzed data types such as usual dietary intake records, or the self-administered questionnaire regarding current dietary control. This difference may be due to variations between evaluations of healthy diet consumption by dietary-intake records and subjects' perceived efforts of dietary control, which demonstrated different adherence to dietary control. Previous studies demonstrated that dietary control and physical activity constitute the core MetS interventions [12-15]. The adherence to dietary control and physical activity in this study is lower than previous studies, which suggests that effective interventions may be necessary for menopausal women to improve their compliance with dietary control and physical activity.

Second, women who applied dietary control strategies to improve their health were more likely to be in the 40-49 age group (OR: 3.38; CI: 1.25-9.18), engage in physical activity (OR: 2.24;CI: 1.43-3.52) and take hypertension medication (OR: 1.66; CI: 1.39-3.30) or diabetes mellitus medication (OR: 2.99; CI: $1.80-4.97)$. In the current study, compared to the 60-64 age group, the OR for adherence to dietary control in the 40-49 age group was 3.38-fold higher. These findings are similar to previous studies, which stated that lifestyle modifications increase with age [27] and those in their 40s are more likely to maintain a healthy lifestyle, whereas those in their 60s and older are less likely to maintain a healthy lifestyle [28]. Thus, considering that lifestyle-modification compliance increases with age, it is necessary to develop a strategy based on age to improve healthy diet control. Given our result of the 2.238-fold higher OR for compliance with dietary control in the physical activity group, these findings are similar to previous studies, which state that physical activity affects individuals' healthy nutritional needs [29] and increased physical activity improves eating habits [30]. In this study, the OR for dietary control adherence in taking hypertension medication or diabetes mellitus medication were significantly higher. Similarly, previous studies reported that perceived health status and perceived disease status such as diagnosed diseases, health examination, and prescribed medications for those diseases improve healthy lifestyle compliance [31,32]. Our findings that taking anti-hypertensive medication or anti-diabetic medication was positively related to dietary control adherence are considered to be the same results as those in previous studies which found that the perceived health status motivates them to practice lifestyle modification such as diet control [31,32]. The result suggests that it is necessary to have regular health examinations and educational consultations regarding MetS symptoms and complications to improve their perceived health status and support dietary control in menopausal MetS women.

Finally, physically active menopausal women with MetS were more likely to also engage in dieting (OR: 2.32; CI: 1.42-3.51). Compared with this result, previous studies reported that food intake and physical activity associate with each other [33-35]. As this study only included mid-intensity and high-intensity physical activity, this may limit our understanding of the more detailed associated factors that increase physical-activity adherence. Future studies must explore more detailed data on physical activity, such as exercise frequency and exercise type, for example walking, balanced training, and strength training.

The design of this study had some limitations. First, because of its cross-sectional nature, we provided representative results based on KNHANES, but we could not prove that causal relationships exist between lifestyle factors. Second, there may be information bias due to using self-reported data to analyze associated factors of lifestyle modification. Third, we had limited information on other influencing factors, such as knowledge, motivation, social support, and self-efficacy [36], regarding MetS healthy lifestyles. Therefore, we had to obtain detailed information about dietary control and 
physical activity. Examining more detailed dietary patterns, including eating habits, frequency of eating alone and dining out, nutrient profile, and whether subjects skip meals, would help us to better suggest associated lifestyle factors to increase dietary control compliance. A prospective design study is necessary to investigate dietary control and physical activity compliance, including the more detailed lifestyle features.

\section{Conclusions}

We found that the associated lifestyle factors associated with dietary control in menopausal women are within the 40-49 age group who are physically active and take hypertension or diabetes mellitus medication. Our study also showed that adherence to physical activity in menopausal women relates to dietary control. These results support the beneficial impact of customized interventions considering age, compliance to lifestyle, perception of disease, and health status. Accordingly, suggestions can be provided to healthcare workers for designing not only individual approaches to lifestyle modification but also comprehensive intervention including dietary control and physical activity for menopausal MetS women. Health-care interventions like dietary control providing additional support to vulnerable MetS women should target those aged 60 or over those who do not take medicines related to hypertension and diabetes mellitus.

Author Contributions: Conceptualization, G.L. and H.Y.C.; Methodology, H.Y.C. and G.L.; Formal analysis, H.Y.C. and G.L.; Data Curation, H.Y.C. and G.L.; Writing-Original Draft preparation, G.L. and H.Y.C.; Writing-Review \& Editing, H.Y.C. and G.L.; All authors have read and agreed to the published version of the manuscript.

Funding: This research received no external funding.

Conflicts of Interest: The authors declare no conflict of interest.

\section{References}

1. Stefanska, A.; Bergmann, K.; Sypniewska, G. Metabolic syndrome and menopause: Pathophysiology, clinical and diagnostic significance. Adv. Clin. Chem. 2015, 72, 1-75. [CrossRef] [PubMed]

2. Janssen, I.; Powell, L.H.; Crawford, S.; Lasley, B.; Sutton-Tyrrell, K. Menopause and the metabolic syndrome: The Study of Women's Health Across the Nation. Arch. Intern. Med. 2008, 168, 1568-1575. [CrossRef] [PubMed]

3. Alberti, K.G.; Eckel, R.H.; Grundy, S.M.; Zimmet, P.Z.; Cleeman, J.I.; Donato, K.A.; Fruchart, J.C.; James, W.P.; Loria, C.M.; Smith, S.C.; et al. Harmonizing the metabolic syndrome: A joint interim statement of the International Diabetes Federation Task Force on Epidemiology and Prevention; National Heart, Lung, and Blood Institute; American Heart Association; World Heart Federation; International Atherosclerosis Society; and International Association for the Study of Obesity. Circulation 2009, 120, 1640-1645. [CrossRef] [PubMed]

4. Saklayen, M.G. The global epidemic of the metabolic syndrome. Curr. Hypertens. Rep. 2018, 20. [CrossRef]

5. Kim, M.H.; Lee, S.H.; Shin, K.S.; Son, D.Y.; Kim, S.H.; Joe, H.; Yoo, B.W.; Hong, S.H.; Cho, C.Y.; Shin, H.S.; et al. The change of metabolic syndrome prevalence and its risk factors in Korean adults for decade: Korea National Health and Nutrition Examination Survey for 2008-2017. Korean J. Fam Pract. 2020, 10, 44-52. [CrossRef]

6. Rask, M.C.; Kahn, C.R. Tissue-specific insulin signaling, metabolic syndrome and cardiovascular disease. Arterioscler. Thromb. Vasc. Biol. 2012, 32, 2052-2059. [CrossRef]

7. Redon, P.; Maloberti, A.; Facchetti, R.; Redon, J.; Lurbe, E.; Bombelli, M.; Mancia, G.; Grassi, G. Gender-related differences in serum uric acid in treated hypertensive patients from central and east European countries: Findings from the Blood Pressure control rate and CArdiovascular Risk profilE study. J. Hypertens. 2019, 37, 380-388. [CrossRef]

8. Maloberti, A.; Bruno, R.M.; Facchetti, R.; Grassi, G.; Taddei, S.; Ghiadoni, L.; Giannattasio, C. The role of metabolic syndrome in blood pressure control and pulse wave velocity progression over a 3.5 years in treated hypertensive PATIENTS. Eur. J. Intern. Med. 2020, 76, 107-109. [CrossRef] 
9. Gurka, M.J.; Vishnu, A.; Santen, R.J.; DeBoer, M.D. Progression of metabolic syndrome severity during the menopausal transition. J. Am. Heart Assoc. 2016, 5, e003609. [CrossRef]

10. Stone, N.J.; Schmeltz, L.R. Metabolic syndrome management. Expert. Opin. Pharmacother. 2007, 8, $2059-2075$. [CrossRef]

11. Rochlani, Y.; Pothineni, N.V.; Kovelamudi, S.; Mehta, J.L. Metabolic syndrome: Pathophysiology, management, and modulation by natural compounds. Ther. Adv. Cardiovasc. Dis. 2017, 11, 215-225. [CrossRef] [PubMed]

12. Pérez, E.A.; González, M.P.; Martínez-Espinosa, R.M.; Vila, M.D.; Reig, G.G. Practical guidance for interventions in adults with metabolic syndrome: Diet and exercise vs. changes in body composition. Int. J. Environ. Res. Public Health 2019, 16, 3481. [CrossRef] [PubMed]

13. Ratner, R.; Goldberg, R.; Haffner, S.; Marcovina, S.; Orchard, T.; Fowler, S.; Temprosa, M.; Diabetes Prevention Program Research Group. Impact of intensive lifestyle and metformin therapy on cardiovascular disease risk factors in the diabetes prevention program. Diabetes Care. 2005, 28, 888-894. [CrossRef] [PubMed]

14. Watkins, L.L.; Sherwood, A.; Feinglos, M.; Hinderliter, A.; Babyak, M.; Gullette, E.; Waugh, R.; Blumenthal, J.A. Effects of exercise and weight loss on cardiac risk factors associated with syndrome X. Arch. Intern. Med. 2003, 163, 1889-1895. [CrossRef]

15. Fappa, E.; Yannakoulia, M.; Pitsavos, C.; Skoumas, I.; Valourdou, S.; Stefanadis, C. Lifestyle intervention in the management of metabolic syndrome: Could we improve adherence issues? Nutrition 2008, 24, 286-291. [CrossRef]

16. Lee, J.A.; Cha, Y.H.; Kim, S.H.; Park, H.S. Impact of combined lifestyle factors on metabolic syndrome in Korean men. J. Public Health 2017, 39, 82-89. [CrossRef]

17. Slagter, S.N.; van Vliet-Ostaptchouk, J.V.; Vonk, J.M.; Boezen, H.M.; Dullaart, R.P.; Kobold, A.C.; Feskens, E.J.; van Beek, A.P.; van der Klauw, M.M.; Wolffenbuttel, B.H. Combined effects of smoking and alcohol on metabolic syndrome: The LifeLines cohort study. PLoS ONE 2014, 9, e96406. [CrossRef]

18. Korea Centers for Disease Control and Prevention. Guide to the Utilization of the Data from the seventh Korean National Health and Nutrition Examination Survey (KNHANES VII-1 \&2). Available online: https://knhanes.cdc.go.kr/knhanes/sub03/sub03_06_02.do (accessed on 2 April 2020).

19. Grundy, S.M.; Cleeman, J.I.; Daniels, S.R.; Donato, K.A.; Eckel, R.H.; Franklin, B.A. Diagnosis and management of the metabolic syndrome: An American Heart Association/National Heart, Lung, and Blood Institute Scientific Statement. Circulation 2005, 112, 2735-2752. [CrossRef]

20. Kim, M.K.; Lee, W.Y.; Kang, J.H.; Kang, J.H.; Kim, B.T.; Kim, S.M. 2014 Clinical practice guidelines for overweight and obesity in Korea. Endocrinol. Metab. 2014, 29, 405-409. [CrossRef]

21. Smith, U. Smoking elicits the insulin resistance syndrome: New aspects of the harmful effect of smoking. J. Intern. Med. 1995, 237, 435-437. [CrossRef]

22. Facchini, F.S.; Hollenbeck, C.B.; Jeppesen, J.; Chen, Y.D.; Reaven, G.M. Insulin resistance and cigarette smoking. Lancet 1992, 339, 1128-1130. [CrossRef]

23. Kong, C.; Nimmo, L.; Elatrozy, T. Smoking is associated with increased hepatic lipase activity, insulin resistance, dyslipidaemia and early atherosclerosis in Type 2 diabetes. Atherosclerosis 2001, 156, 373-378. [CrossRef]

24. Marlatt, K.L.; Beyl, R.A.; Redman, L.M. A qualitative assessment of health behaviors and experiences during menopause: A cross-sectional, observational study. Maturitas 2018, 116, 36-42. [CrossRef] [PubMed]

25. Mansikkamäki, K.; Raitanen, J.; Malila, N.; Sarkeala, T.; Männistö, S.; Fredman, J.; Heinävaara, S.; Luoto, R. Physical activity and menopause-related quality of life-A population-based cross-sectional study. Maturitas 2015, 80, 69-74. [CrossRef]

26. Cho, Y.A.; Kim, J.; Cho, E.R.; Shin, A. Dietary patterns and the prevalence of metabolic syndrome in Korean women. Nutr. Metab. Cardiovasc. Dis. 2011, 21, 893-900. [CrossRef]

27. Beşer, A.; Bahar, Z.; Büyükkaya, D. Health promoting behaviors and factors related to lifestyle among Turkish workers and occupational health nurses' responsibilities in their health promoting activities. Ind. Health 2007, 45, 151-159. [CrossRef]

28. Lee, J.E.; Lee, E.J. Changes in risk factors of metabolic syndrome by health behavior compliance rates. J. Korean Data Inf. Sci. Soc. 2017, 28, 559-571. [CrossRef]

29. Evans, W.J.; Cyr-Campbell, D. Nutrition, exercise, and healthy aging. J. Am. Diet. Assoc. 1997, 97, 632-638. [CrossRef] 
30. Mohammadi, M.; Ramezankhani, A.; Mohammadi, S.; Zahed, S.; Khabiri, F.; Khodakarim, S.; Roshani, M.; Ghayur, M. The predictors of metabolic syndrome based on Walker Health-Promoting lifestyle in Iran 2016. Diabetes Metab Syndr. 2017, S745-S749. [CrossRef]

31. Taechaboonsermsak, P.; Kaewkungwal, J.; Singhasivanon, P.; Fungladda, W.; Wilailak, S. Causal relationship between health promoting behavior and quality of life in cervical cancer patients undergoing radiotherapy. Southeast. Asian J. Trop. Med. Public Health 2005, 36, 1568-1575.

32. Kang, J.S.; Kang, H.S.; Yun, E.K.; Choi, H.R. Factors influencing health behavior compliance of patients with metabolic syndrome. Korean J. Adult Nurs. 2012, 24, 191-199. [CrossRef]

33. Sallis, J.F.; Glanz, K. Physical activity and food environments: Solutions to the obesity epidemic. Milbank Q. 2009, 87, 123-154. [CrossRef] [PubMed]

34. Motlagh, Z.; Mazloomy-Mahmoodabad, S.; Momayyezi, M. Study of Health-promotion behaviors among university of medical science students. Zahedan J. Res. Med. Sci. 2011, 13, e93999.

35. Blair, S.N.; Jacobs, D.R., Jr.; Powell, K.E. Relationships between exercise or physical activity and other health behaviors. Public Health Rep. 1985, 100, 172-180.

36. Lee, G.; Yang, S.J.; Chee, Y.K. Assessment of healthy behaviors for metabolic syndrome among Korean adults: A modified information-motivation-behavioral skills with psychological distress. BMC Public Health 2016, 16, 518. [CrossRef]

(C) 2020 by the authors. Licensee MDPI, Basel, Switzerland. This article is an open access article distributed under the terms and conditions of the Creative Commons Attribution (CC BY) license (http://creativecommons.org/licenses/by/4.0/). 